\title{
COMMENTARY
}

\section{Call to Integrate Content Related to Disabilities into Contemporary Pharmacy Curricula}

\author{
Michelle L. Blakely, PhD, MEd ${ }^{\mathrm{a}, \mathrm{b}}$ \\ ${ }^{a}$ University of Wyoming, School of Pharmacy, Laramie, Wyoming \\ ${ }^{\mathrm{b}}$ Editorial Board Member, American Journal of Pharmaceutical Education, Arlington, Virginia
}

Corresponding Author: Michelle L. Blakely, University of Wyoming, School of Pharmacy, 1000 E. University Ave., Dept. 3375, Laramie, WY 82071. Tel: 307-766-6171. Email: Michelle.blakely@uwyo.edu

Submitted September 2, 2021; accepted November 8, 2021; ePublished November 2021

Keywords: patients, disabilities, health care education, pharmacy, communication

\section{INTRODUCTION}

Although the United States (U.S.) is a leader in health care technology, patient care has not yet reached an equitable status for all populations. For patients with disabilities, obtaining access to health care services, as well as communicating with health care professionals, can be a challenging experience. ${ }^{1}$ In fact, during health care interactions, patients with disabilities have reported feeling uncomfortable and have experienced negative feelings such as fear, anxiety and mistrust toward health care providers. ${ }^{2}$ Moreover, previous research has shown that pharmacists do not feel prepared to understand or serve patients with disabilities. ${ }^{3,4,8}$ A lack of proper access to health care services, ineffective communication, and/or negative health care interactions may lead to avoidance of care, poor patient understanding of treatment options, and a lower quality of life. ${ }^{1}$

Most schools/colleges of pharmacy core curricula provide students with only a brief introduction to patients with disabilities, which is usually through didactic content.$^{5-8}$ While these brief introductions are helpful, pedagogical approaches do not provide comprehensive content for mastery of skills and strategies for providing accessible health care services to patients with disabilities. ${ }^{5}$ Student pharmacists would benefit from additional education and/or training specifically related to patients with disabilities. Improving student pharmacists' knowledge and understanding of this patient population would help to increase their competence, confidence and skills in communicating with, and providing care to, this population.

\section{Disability Definitions/Descriptions}

The Americans with Disabilities Act Amendments Act (ADAAA) defines disability as "an impairment that substantially limits one or more major life activities, a record of such an impairment, or being regarded as having such an impairment." "The World Health Organization (WHO) and the International Classification of Functioning, Disability, and Health (ICF), which provides a framework for the measurement of functioning and disability, defines disability as an "umbrella term, covering impairments, activity limitations, and participation restrictions." 10,11 Regardless of which agency definition is used, the term disability traditionally encompasses various categories of impairments, activity limitations, and restrictions that includes visual, hearing, motor, and cognitive/learning impairments, as well as those pertaining to speech.

The Individuals with Disabilities Education Act (IDEA) provides generally recognized definitions or descriptions for each disability category. ${ }^{12}$ For example, according to IDEA, an individual has a visual impairment if they experience vision loss that cannot be corrected whereas hearing impairments can be changeable or permanent. ${ }^{12}$ Motor impairments are the partial or complete loss of functioning of a body part, and cognitive or learning impairments are defined as "a disorder in one or more psychological processes that are important for understanding and using language". ${ }^{12}$ Speech and language disabilities include stuttering and other vocal impairments. ${ }^{12}$ Please note that this is not a comprehensive list of all disabilities that individuals may live with, many individuals live with more than one disability and the disabilities may not always be readily apparent to others. In fact, many individuals live with less obvious disabilities that are referred to as "hidden" or "invisible." According to the WHO, approximately one billion individuals across the world live with some type of disability, which represents nearly $15 \%$ of the worldwide population, and approximately $26 \%$ of U.S. adults. ${ }^{11,13}$ Approximately $20-50 \%$ of all individuals with disabilities do not take their medications as prescribed. ${ }^{14}$

\section{DISCUSSION}

Suggestions for Integrating Content Related to Disabilities into Curricula 
Content related to disabilities can be integrated in various ways across the curricula. For example, faculty may seek volunteers with disabilities from the local community to visit classrooms to provide their unique perspectives regarding their health care experiences. Time permitting, a panel discussion of volunteers would prove educational for students. ${ }^{15}$ These learning opportunities give student pharmacists firsthand insight into challenges faced by patients with disabilities and provides them with perspectives on how to more effectively facilitate communication with this population. If recruiting community volunteers is not a viable option, the use of simulation learning via objective structured clinical exams (OSCE) may be a useful alternative. These role-played scenarios can provide opportunities for student pharmacists to practice communicating with a simulated patient with a disability. Simulation learning activities can be used to augment corresponding didactic content while providing students opportunities to apply the skills/knowledge they have learned.

Other approaches/content can focus on using the teach-back method, motivational interviewing, use of appropriate facial expressions, communicating directly with the patient (with/without an interpreter for those who are deaf/hard of hearing), integrating visual aids to enhance verbal and written communication, and using bullet points to highlight key pieces of information in written communication. ${ }^{1,2,4}$ Student pharmacists can also benefit from education and training on disability culture to enhance their knowledge, clarify common misconceptions, improve attitudes, and increase communication competence and confidence. ${ }^{4}$ Providing interprofessional education (IPE) training opportunities for communicating with patients with disabilities can provide valuable learning experiences for a variety of health professions' students.

\section{Assessments of Content Mastery}

Communication course laboratories traditionally use OSCEs as the assessment method of choice to evaluate mastery of content and skill development for effective communication. Using simulated patients with disabilities OSCEs can be helpful in providing pharmacy students the opportunity to apply strategies for successful communication in simulated health care interactions. These practices may help student pharmacists to increase their competence and confidence in interacting with patients with disabilities.

Other types of assessments can also be used to evaluate mastery of disability content. For example, peer evaluations can be used with OSCEs to obtain a more comprehensive perspective of the student pharmacists' skills, competence and confidence. Additionally, the individuals who role-play patients with disabilities can provide their assessments of the student pharmacists' ability to effectively communicate with a simulated patient. Reflections are yet another option for assessing skill development and knowledge. If OSCEs are recorded, the student pharmacist can fully perform a self-assessment; this is a great way for students to review their interactions and to self-evaluate skill development and application. Quizzes and exams can also be used to evaluate student knowledge and application of skills. Furthermore, written assignments that use patient case scenarios can be helpful in assessing student mastery of content as well as skill acquisition. Lastly, interprofessional education (IPE) activities related to disabilities can provide unique opportunities to assess student pharmacist skill acquisition and mastery of content in a team-based environment.

\section{Research on Patients with Disabilities}

There is a dearth of information pertaining to patients with disabilities and health care interactions. Much of the available literature does not directly include the perspectives of patients with disabilities regarding health care and access. The few articles that were identified for this commentary focus on deaf/hard-of-hearing patients, interactions with physicians or on broader concepts such as use of professionalism with patients with disabilities. ${ }^{1-5,16,17}$ In order to have more comprehensive content related to disabilities for pharmacy curricula, it is imperative that researchers include patients with disabilities' perspectives and conduct studies based on their needs and experiences. Insight from this patient population is essential to inform curricula, policies, and processes in educational, community, and hospital settings.

\section{Effective Communication with Patients with Disabilities}

To effectively provide care to a patient with a disability, it is essential for student pharmacists to understand that they must first ascertain the patient's preferred mode of communicating. Then, to the extent possible, they should honor the patient's request to communicate in that mode for the duration of the interaction. There are a variety of different modes of communication for patients with disabilities and identifying and using those that the patient prefers will produce a more successful encounter. Some tips given to student pharmacists for developing effective health communication skills when interacting with patients with disabilities include: (1) use plain language, (2) limit information to three to five key points, (3) be specific and concrete, (4) use visuals, (5) include a summary that repeats the key points, and (6) use positive, hopeful, and empowering language..$^{5}$ 


\section{CALL TO ACTION}

Student pharmacists' need to obtain the requisite education, knowledge and skills to provide effective health care to individuals with disabilities. Therefore, it is essential that schools/colleges of pharmacy prepare student pharmacists to provide effective care to patients with disabilities. Schools/colleges of pharmacy should aim to train pharmacists to be competent and confident in providing care to this patient population. In order to accomplish this, we must provide educational content related to disabilities in pharmacy curriculum. Looking forward, this should be an important goal for the Academy. Since the Accreditation Council for Pharmacy Education (ACPE) Accreditation Standards are currently under revision, this is the perfect opportunity for the Academy to address these missing pieces in contemporary pharmacy education. ${ }^{18}$

\section{CONCLUSION}

Regardless of disability type, individuals with disabilities may encounter unique barriers that impede health care access. It is important to recognize that each patient is an individual and to tailor care to each patient's specific needs and preferences. Ineffective communication between pharmacists and patients with disabilities impedes the establishment of rapport and may result in a strained relationship. ${ }^{3,19}$ This can widen health care disparities, negatively affect treatment outcomes, result in a lack of knowledge regarding health issues, and can ultimately lead to avoidance of care. ${ }^{1,19}$ Improving student pharmacists' competence, confidence and skills in providing care to patients with disabilities will increase patients' knowledge of their health care and associated treatments, ensure safer medication use, and optimize patient health-related outcomes. ${ }^{1,4}$ Hence, to ensure equity in health care services, it is vital that student pharmacists obtain the knowledge and skills necessary to provide effective health services to individuals with disabilities. Since the ACPE Accreditation Standards for 2025 are currently under development, this provides the Academy the ideal opportunity to recognize the need to include content related to disabilities within contemporary pharmacy curricula. ${ }^{18}$

\section{REFERENCES}

1. Iezzoni L, O'Day B, Kileen M, Harker H. Communicating about health care: observations from persons who are deaf or hard of hearing. Ann Intern Med. 2004;140(5):356-632. doi: 10.7326/0003-4819-140-5-20040302000011 .

2. Steinberg A, Barnett S, Meador H, Wiggins E, Zazove P. Health care system accessibility experiences and perceptions of deaf people. J Gen Intern Med. 2006;21(3):260-266. doi: 10.1111/j.1525-1497.2006.00340.x.

3. Barnett S. Communication with deaf and hard-of-hearing people: a guide for medical education. Acad Med. 2002;77(7):694-700. doi:10.1097/00001888-200207000-00009.

4. Ferguson M, Liu M. Communication needs of patients with altered hearing ability: informing pharmacists' patient care services though focus groups. J Am Pharm Assoc. 2015;55(2):153-160. doi:10.1331/JAPhA.2015.14147.

5. Blakely ML, Salvo MC. Improving communication between healthcare professionals and deaf and hard of hearing patients. Res Social Adm Pharm. 2019;15(9):1193e1194. doi:10.1016/j.sapharm.2019.03.076.

6. Smith WT, Roth JJ, Okoro O, Kimberlin C, Folakemi TO. Disability in cultural competency pharmacy education. Am J Pharm Ed. 2011; 75(2): 26. doi:10.5688/ajpe75226.

7. Peiris-John R, Jain NR, Hogan A, Ameratunga S. Educating health science students about disability: teachers' perspectives on curricular gaps. Disabil Health J. 2021; 14(1): 100985. doi: https://doi.org/10.1016/j.dhjo.2020.100985.

8. Smith WT, Catney CM, Rickles NM, et al. Pharmacy student comfort in communicating with persons with disabilities. Curr Pharm Teach Learn. 2014; 6(2): 175-184. doi: https://doi.org/10.1016/j.cptl.2013.11.011.

9. US Department of Labor. ADA amendments act of 2008 frequently asked questions. January 2009. Available at: https://www.dol.gov/agencies/ofccp/faqs/americans-with-disabilities-act-amendments. Published 2009. Accessed November 6, 2021.

10. World Health Organization. Health topics: disabilities. Available at: https:/www.who.int/topics/disabilities/en/. Published 2021. Accessed November 6, 2021.

11. World Health Organization. Disability and health. 2020. Available at: https://www.who.int/news-room/factsheets/detail/disability-and-health. Published 2020. Accessed on November 6, 2021.

12. Individual with Disabilities Education Act. Sec. 300.8 (C). May 2018. Available at: https://sites.ed.gov/idea/regs/b/a/300.8/c/. Published 2018. Accessed November 6, 2021. 
13. Centers for Disease Control and Prevention. Disability and health promotion. September 2020. Available at: https://www.cdc.gov/ncbddd/disabilityandhealth/infographic-disability-impacts-all.html. Published 2020. Accessed November 6, 2021.

14. Schwartz JK, Unni E. Inclusion of people with disabilities in research to improve medication adherence: a systematic review. Patient Prefer Adherence. 2021:15;1671-1677. doi:10.2147/PPA.S314135.

15. O'Connell MB, Rodriguez de Bittner M, Poirier T, et al. Cultural competency in health care and its implications for pharmacy part 3a: emphasis on pharmacy education, curriculums, and future directions. Pharmacotherapy. 2013; 33(12): e347-e367. doi: 10.1002/phar.1353.

16. Baumbusch J, Phinney A, Baumbusch. Practising family medicine for adults with intellectual disabilities. Canadian Fam Med. 2014; 60:e356-e361. https://www.cfp.ca/content/cfp/60/7/e356.full.pdf

17. Bulk LY, Drynan D, Murphy S, et al. Patient perspectives: four pillars of professionalism. J Patient Exp. 2019; 6(3): 74-81. doi: https://doi.org/10.35680/2372-0247.1386.

18. Accreditation Council for Pharmacy Education. ACPE PharmD Program Accreditation - Call for Comments Standards 2025. Available at: https://www.acpe-accredit.org/pharmd-call-for-comments-standards-2025/. Published 2021. Accessed November 6, 2021.

19. Steinberg A, Wiggins E, Barmada C, Sullivan V. Deaf women: experiences and perceptions of healthcare system access. J Womens Health. 2004;11(8):729-741. doi:10.1089/15409990260363689. 